\title{
Навігація
}

УДК 528.942

С.М. Андрєєв, В.А. Жилін, А.С. Топчий

Національний аерокосмічний університет імені Н.С. Жуковського «ХАІ», Харків

\section{МЕТОДИКА ЗАСТОСУВАННЯ БІБЛІОТЕК КОМП'ЮТЕРНОГО ЗОРУ ДЛЯ ПОБУДОВИ КАРТОГРАФІЧНИХ МОДЕЛЕЙ}

Представлена методика застосування бібліотек комп'ютерного зору для побудови картографічних моделей. Розкриті особливості роботи із типами даних на мові Pуthоп, а також побудована класифікація бібліотек мови Руthon. Розроблена методика також пропонується у вигляді структурної схеми для кращої ї̈ візуалізачії та спрощуення розуміння взаємодї основних етапів роботи при побудові картографічних моделей.

Ключові слова: картографія,типи та формати даних, комп'ютерний зір, програмний ГІС-пакет.

\section{Актуальність та постановка задачі}

У структурах сучасних ГІС-пакетів обов'язково присутні різні за типами засоби розробки. На сьогоднішній день існує безліч ГІС-пакетів для обробки даних систем Д33: ArcGIS, Панорама, Erdas Imagine, QGIS, MapInfo, Quantum GIS, тощо. Всі провідні ГIC мають інструменти для вирішення прикладних ГІСзадач. При цьому під конкретні вимоги користувачів існує необхідність модифікувати кожен ГІС-пакет. Модифікація ГІС-пакетів залежить від засобів розробки конкретної ГIC-системи. Засоби розробки ArcGIS містять у собі Esri Developer Network, який в свою чергу складається з ArcGIS Engine i ArcGIS Runtime.

До засобів розробки також відносять кастомізацію ArcGIS for Desktop, оскільки алгоритми автоматизації обробки даних знаходяться в безперервному процесі модернізації. Додаткові модулі ArcGIS for Desktop реалізуються на мові Python i зручно можуть бути впроваджені в інтерфейс програмного забезпечення ArcGIS. Таким чином поліпшуються засоби та швидкість вирішення прикладних ГІСзадач. Отже, конкретні вимоги користувача можуть бути оптимально задоволені. Продукти середовища Python органічно інтегруються в ArcGIS - це призводить до того, що фахівці ГІС можуть виступати в якості розробників додаткових модулів. Мова програмування Python $є$ безкоштовним відкритим засобом, що сприяє зниженню витрат на удосконалення існуючих ГIC-пакетів, а також збільшення робочих місць серед розробників ГІС-додатків.

Python - потужна та проста для вивчення мова програмування. У ній надано опрацьовані високорівневі структури даних і простий, але ефективний підхід до об'єктно-орієнтованого програмування.

Поєднання витонченого синтаксису та динамічної типізації, суміщених із сутністю інтерпретації програмних кодів, робить Руthon ідеальною мовою для написання сценаріїв та прискореної розробки додатків у різних середовищах розробки й на більшості операційних платформ.

Актуальність даної роботи полягає у якісно новому підході до розробки методики побудови картографічної моделі з використанням бібліотеки комп'ютерного зору і середовища Python.

Метою даної роботи є покращення інформаційних можливостей розробників програмного забезпечення для вирішення тематичних ГІС-задач у відповідності до вимог замовників.

Предметом дослідження є методика побудови картографічної моделі із використанням бібліотек комп'ютерного зору та середовища Python.

Об'єктом дослідження $є$ процес обробки цифрових космічних знімків засобами систем комп'ютерного зору в середовищі Python.

\section{Результати досліджень}

Попередній аналіз середовища Python. Руthon - це мова програмування високого рівня із динамічною типізацією, автоматичним управлінням пам'яттю, із зручними високорівневими структурами даних, такими як словники (хеш-таблиці), списки, кортежі. Велика частина реалізацій Руthon - iнтерпретатори. При цьому Рython підтримує класи, модулі (які можуть бути об'єднані в пакети), обробку винятків, а також багатопотокові обчислення. Python має простий і виразний синтаксис. Мова підтримує кілька парадигм програмування: структурне, об'єктно-орієнтоване, функціональне і аспектно-орієнтоване. Python придатний для більшості активно використовуваних платформ. Він поширюється вільно під дуже ліберальної ліцензією, що дозволяє використовувати його без обмежень в будь-яких додатках. При цьому справедливо буде зауважити, що без наявності хоча б теоретичних знань про об'єктно-орієнтоване програмування, знайомство з Pуthon буде ускладне- 
но. Однак, у Python є й недолік - 3 його допомогою надзвичайно легко передавати найпростішу інформацію, проте не досить зручно висловлювати складні конструкції. В цілому, Python $€$ мовою загального призначення, тому може застосовуватися практично в будь-якій області розробки програмного забезпечення (ПЗ). Стандартні модулі розширення Python — це відмінно спроектована і неодноразово перевірена функціональність для вирішення завдань, що виникають в кожному проекті з розробки ПЗ, обробки рядків і текстів, взаємодія з операційною системою, підтримка Web-додатків. Модулі, що це забезпечують, також написані на мові Python, тому середовище Python має його найпривабливішу властивість кросплатформеність. Модулі розширення для Python можна створювати не тільки на самій мові Python, але й за допомогою інших мов програмування. У цьому випадку з'являється можливість більш ефективної реалізації ресурсномістких завдань, наприклад, складних наукових обчислень, однак втрачається перевага кросплатформеності, якщо мова модуля розширення не є сама по собі кросплатформеною, як Python.

Типи даних Python. Python представляє найбільш типові структури даних, такі як: список, кортеж, словник. Кортеж має незмінну впорядковану послідовність даних. У ньому можуть міститися елементи різних типів, наприклад, інші кортежі. Кортеж визначається в круглих дужках, а його елементи розділяються комами. Список - це змінна впорядкована послідовність елементів. Елементи списку також розділяються комами, але задаються вже в квадратних дужках. Словник є хеш-таблицею, що зберігає елемент разом з його ідентифікаторомключем. Послідовний доступ до елементів виконується теж по ключу, тому одиниця зберігання в словнику - це пара об'єкт-ключ і пов'язаний з ним об'єкт-значення. Словник - це змінна, але не впорядкована колекція, так що порядок елементів в словнику може змінюватися з часом. Задається словник в фігурних дужках. У даній роботі розроблена структура взаємодії бібліотек Python за форматами даних яка представлена на рис. 1.

Аналіз комп'ютерних бібліотек, що придатні для взаємодії із мовою програмування Python. OpenCV (Open Source Computer Vision Library) - це бібліотека комп'ютерного зору, яка поставляється 3 відкритим вихідним програмним кодом. Спектр можливостей даної бібліотеки дуже широкий. У ній зібрано велику кількість алгоритмів для використання технологій комп'ютерного зору.

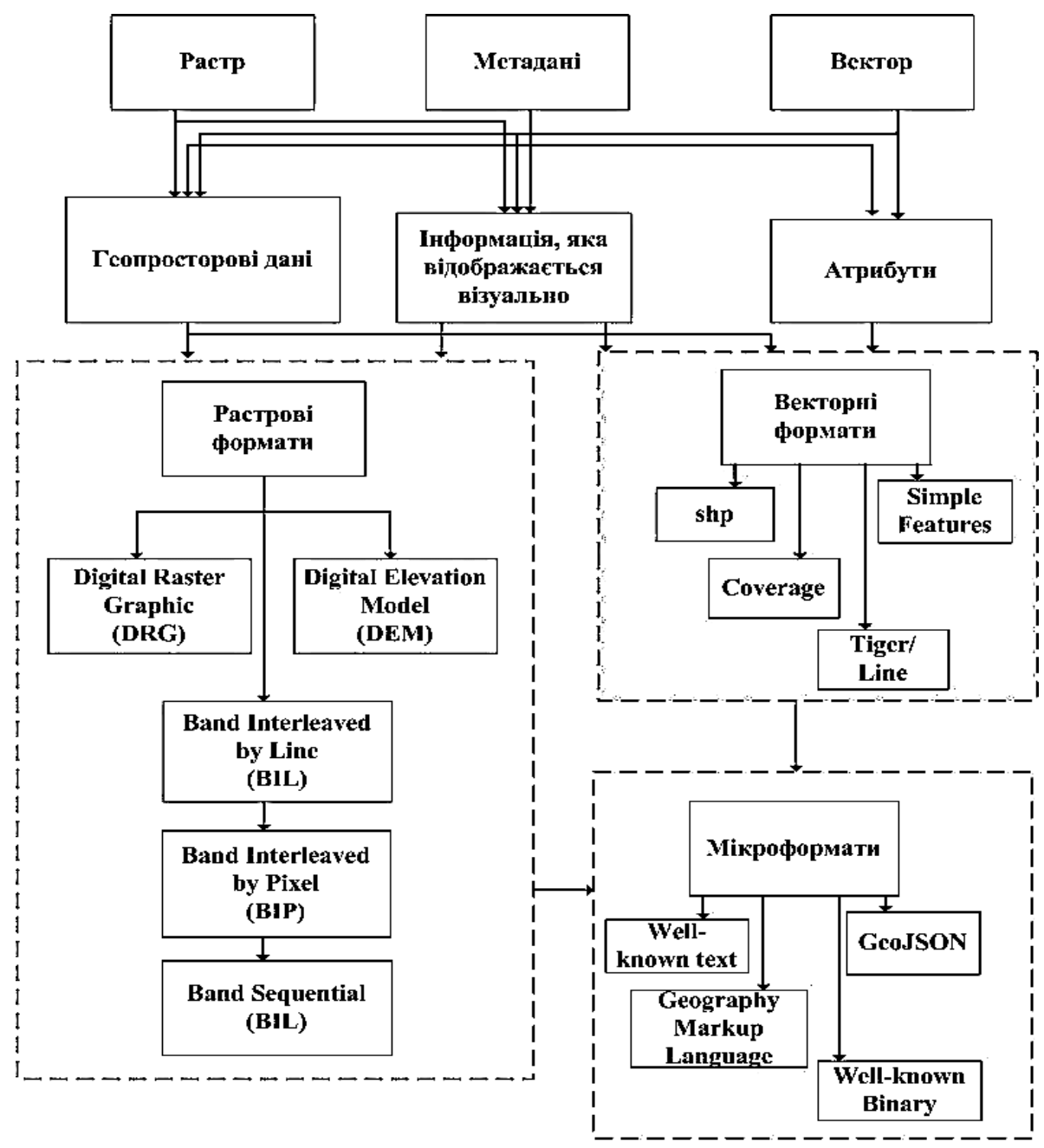

Рис. 1. Структура взаємодії бібліотек Руthon за форматами даних 
OpenCV застосовується для "зшивання" супутникових карт, зменшення шуму медичних зображень, вирівнювання сканованих знімків, аналізу різноманітних фото- та відео-об'єктів, для систем виявлення вторгнення, автоматичного моніторингу і контролю, калібрування відеокамер, в додатках для забезпечення функціонування безпілотних наземних, літальних та підводних апаратів.

Утиліти командного рядку, що входять до складу бібліотеки GDAL, широко використовуються для виконання різноманітних завдань. GDAL — це вільна бібліотека для роботи з растровими даними. Для того, щоб виконати перепроектування, поєднання растрів, обрізку растрів, геотрансформацію, отримати інформацію про кількість каналів растра, вилучити дані та метадані, - встановлюється 15 бібліотека GDAL. Для розрахунку коефіцієнта глобальної кореляції, локальної кореляції і класифікації зон, використовується бібліотека NumPython. Бібліотека NumPython перетворює Python у вільний та більш потужний еквівалент системи. Бібліотека виконує реалізацію матричних та 16 векторних операцій, а також багатьох чисельних алгоритмів.

Matplotlib - бібліотека на мові програмування Python для візуалізації даних двовимірної та тривимірної графіки. Одержувані зображення можуть бути використані у якості ілюстрацій в картографічних публікаціях.

На рис. 2 представлена розроблена структурна схема бібліотек, що використовуються у середовищі мови програмування Python при роботі із геопросторовими даними.

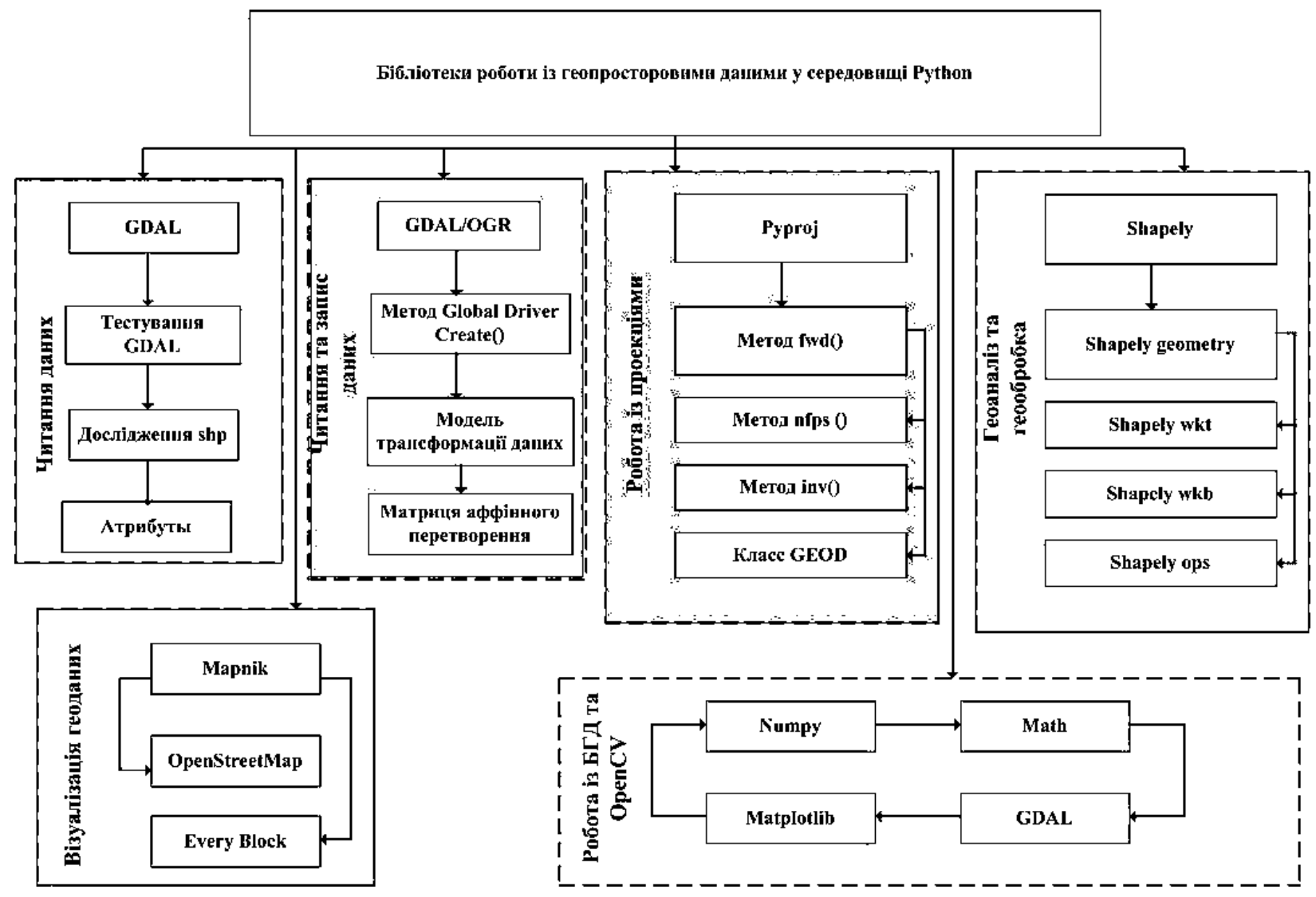

Рис. 2. Структурна схема бібліотек Руthon, що використовуються при роботі із геопросторовими даними

Методика побудови картографічної моделі із застосуванням середовища Python та бібліотеки OpenCV. Для того, щоб розробити методику побудови картографічної моделі з використанням середовища Python і бібліотеки комп'ютерного зору OpenCV, необхідно провести дослідження структури та архітектури мови програмування. Також слід враховувати особливості парадигми мови програмування.

Python має набір безлічі функціональних бібліотек, які можуть бути швидко та ефективно використані для вирішення прикладних ГІС-задач. Для наглядного представлення методика, що пропонується, представлена у вигляді структурної схеми на рис. 3 .
Практичне використання методики побудови картографічних моделей із застосуванням середовища Python та бібліотеки OpenCV. Після того, як дані дистанційного зондування Землі отримано, необхідно виконати первинну обробку знімків, до складу якої входить геометрична корекція, а також корекція яскравості супутникового зображення. Геометрична корекція вбачає афінні, тобто лінійні методи. Корекція яскравості містить просторову фільтрацію, адаптивну фільтрацію, фільтрацію, що виділяє межі елементів на супутниковому зображенні, а також застосування операторів Лапласа та перетворення Фур'є. 


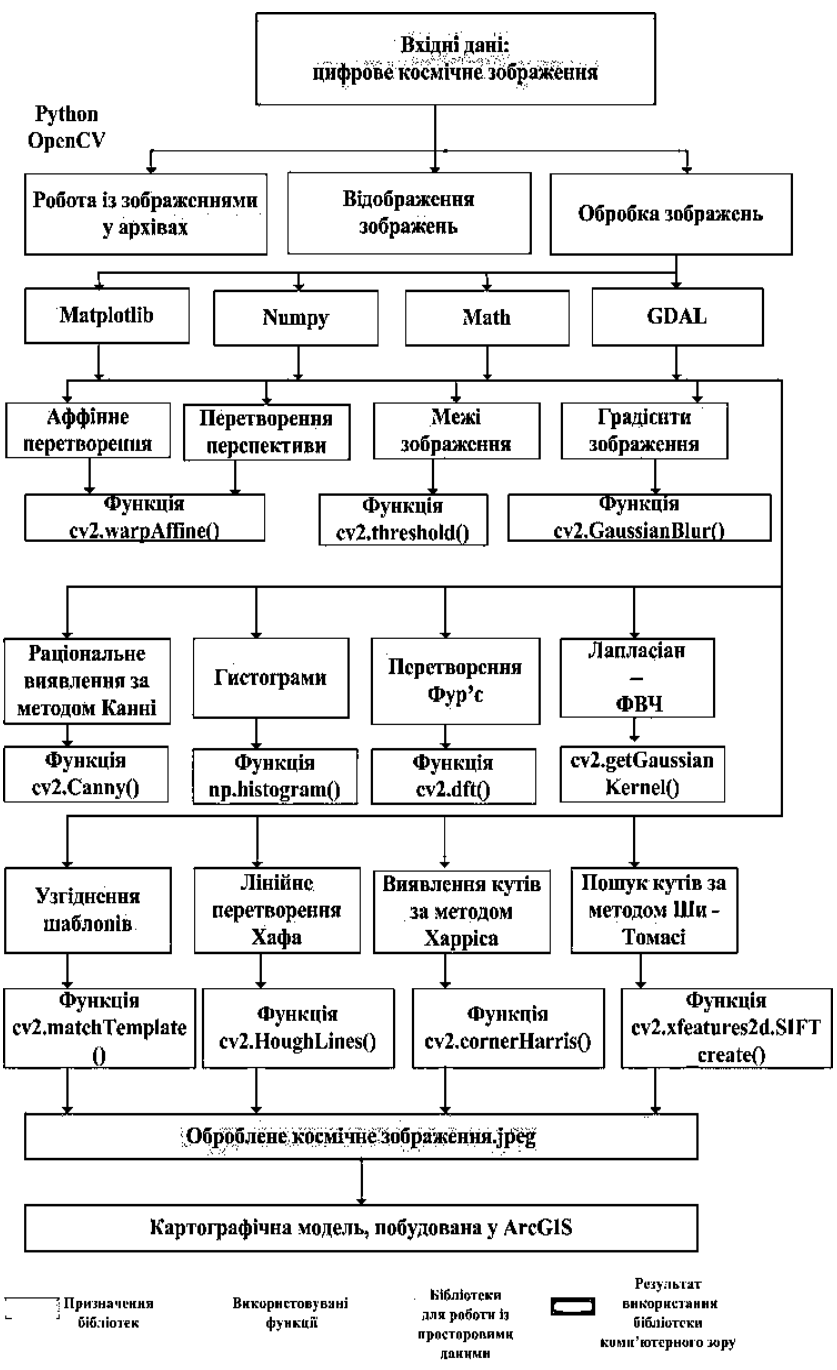

Рис. 3. Методика застосування бібліотек комп'ютерного зору для побудови картографічних моделей

Етапи обробки надано у вигляді структурної схеми на рис. 4 .

Для ілюстрації застосування процедур обробки фотографічного зображення із застосуванням запропонованої методики обрано космічний знімок іспанського міста Росес (рис. 5). А саме, на рис. 6 наведено результат застосування методу виявлення кутів, а на рис. 7 - результат реалізації методу лінійного перетворення Хафа. На рис. 8 наведено картографічну модель міста Росес, розроблену із використанням системи ArcGIS.

\section{Висновки}

Таким чином, в результаті аналізу сучасних ГІС-пакетів, технічних можливостей взаємодії мови Python на рівні впровадження програмних модулів в систему ArcGIS, а також використання потужностей бібліотеки комп'ютерного зору OpenCV в середовищі Python, розроблено структуру взаємодії бібліотек Python за форматами даних, структурну схему бібліотек Python, що використовуються при роботі із геопросторовими даними, а також методику за- стосування бібліотек комп’ютерного зору для побудови картографічних моделей.

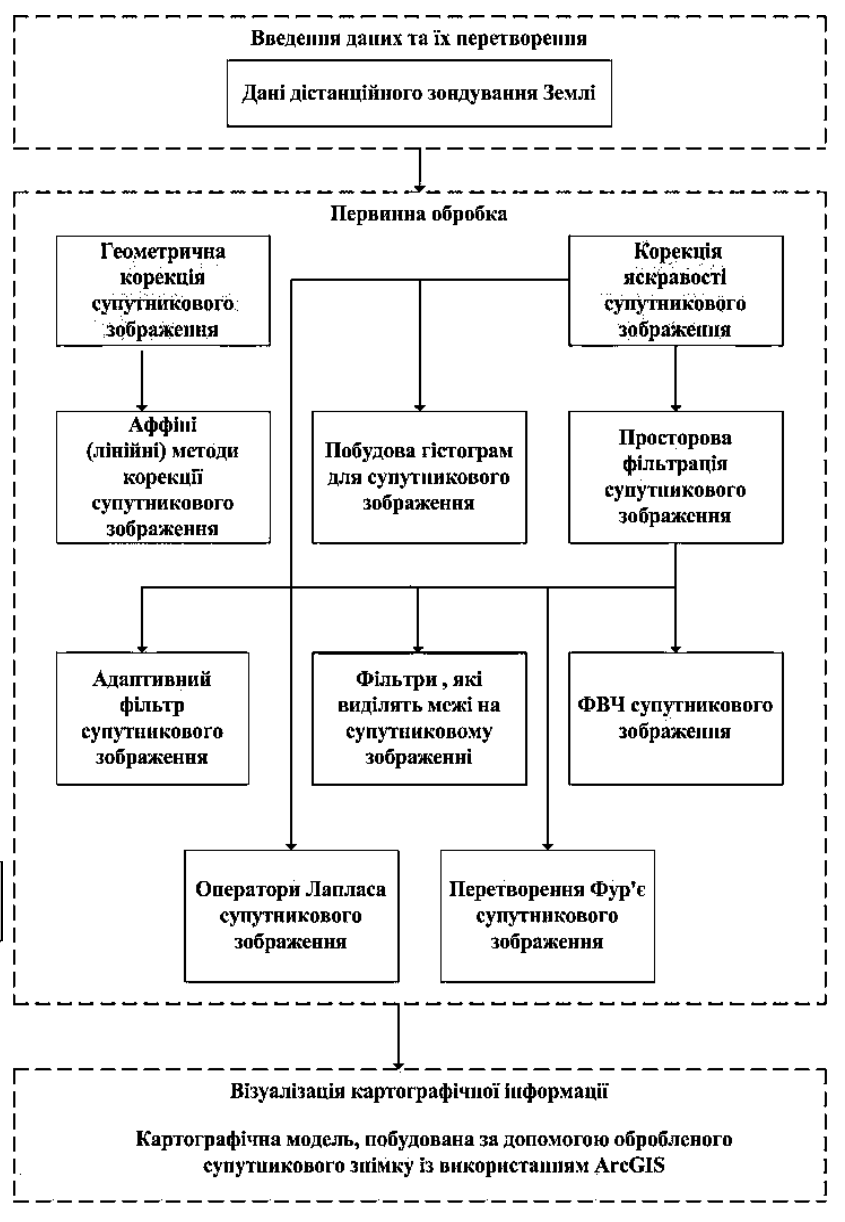

Рис. 4. Етапи обробки цифрового космічного знімку

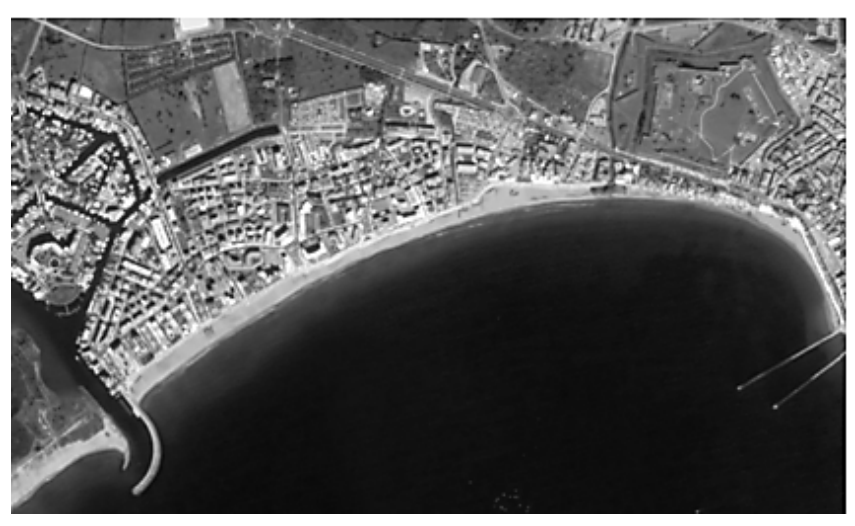

Рис. 5. Космічний знімок міста Росес (Іспанія)

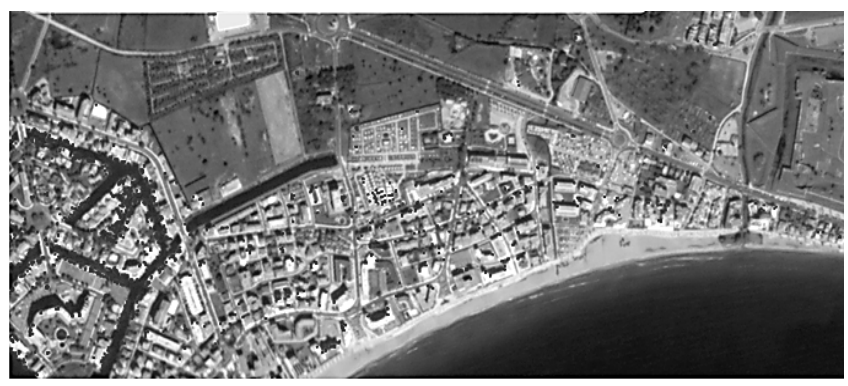

Рис. 6. Результат виявлення кутів на космічному зображенні 


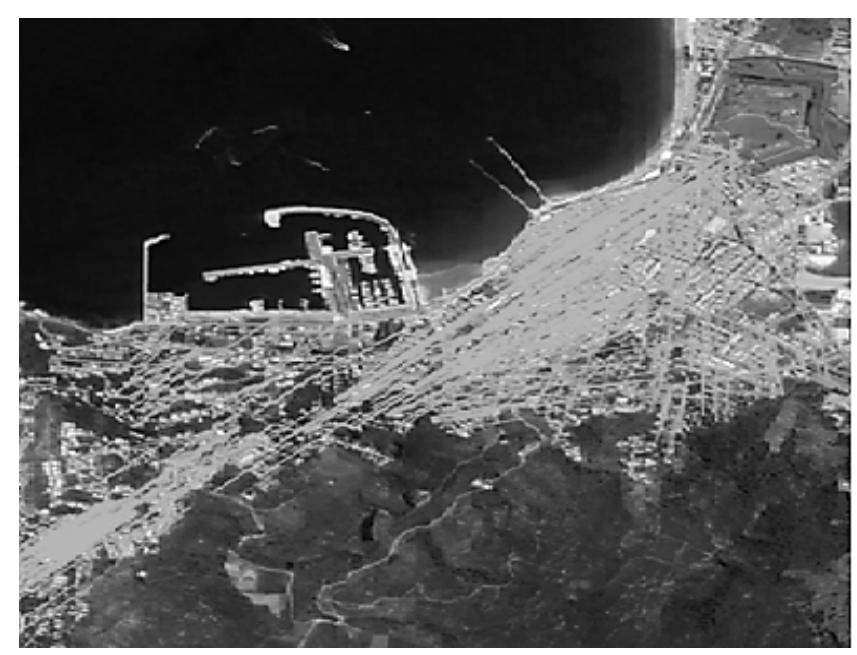

Рис. 7. Результат застосування лінійного перетворення Хафа

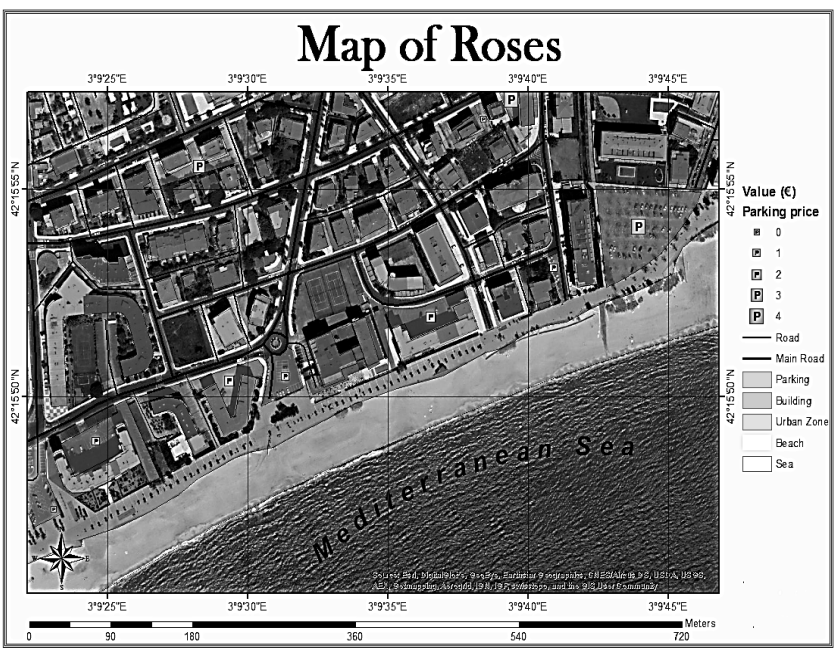

Рис. 8. Публікація карти з електронної картографічної моделі міста Росес (Іспанія)

Наведено результати впровадження розробленої методики для побудови електронної картографічної моделі міста Росес (Іспанія) за даними дистанційного зондування Землі.

\section{Список літератури}

1. Прохорёнок Н.A. Pуthon3. Самое необходимое / Н.А. Прохорёнок, В.А.. Дронов. - СПб.:"БХВ-Петербург", 2016. $-461 c$.

2. Лути Марк. Python. Карманный справочник. 5-е изд.: Пер. с англ.-М.: ООО "И. Д. Вильямс", 2015. $320 \mathrm{c}$.

3. Уэс Маккинли. Python и анализ данных / Пер. с англ. А.А. Слинки. - М.: ДМК Пресс, 2015. — 482 с. C. 14-21, 23-24, 57-70, 244-275.

4. Саммерфилд М. Программирование на Pуthon 3. Подробное руководство. - Пер. с англ. - СПб.: СимволПлюс, 2009. - 608 с.. - С. 552-556.

5. Доусон М. Программируем на Python. - СПб.: Питер, 2014. - 416 с.: ил. - С. 277-307.

6. OpenCV-Python Tutorials [Электронный pecypc]. Режим доступа:

http://docs.opencv.org/master/tutorial_py_root.html\#gsc.tab $=0$.

7. Python [Электронный ресурс]. - Режим достуna: https:// http://dimonvideo.ru/articles/1368/.

8. Разработка Python. Python на Хабре. [Электронный ресурс]. - Режим доступа:

https://habrahabr.ru/post/150302/.

9. Python 3.1. Учебник [Электронный ресурс].Pежим docmyna: https://ru.wikibooks.org.

10. Python 3 для начинающих. Часть 1: начало работы [Электронный ресурс]. - Режим доступа:

http://pythonworld.ru/numpy/1.html.

11. Python 3 для начинаюших. Модуль Math [Электронный ресурс] // - Режим доступа:

http://pythonworld.ru/moduli/modul-math.html.

12. GDAL. GIS-LAB [Электронный ресурс]. Режим docmyna: http://gis-lab.info/.

13. Снимки Landsat 8. USGS [Электронный ресурс].Режим доступа: https://www.usgs.gov/.

14. Python 3 для начинающих. Модуль Matplotlib [Электронный ресурс]. - Режим доступа: http://pythonworld.ru/moduli/modul-matplotlib.html.

\section{МЕТОДИКА ПРИМЕНЕНИЯ БИБЛИОТЕК КОМПЬЮТЕРНОГО ЗРЕНИЯ ДЛЯ ПОСТРОЕНИЯ КАРТОГРАФИЧЕСКИХ МОДЕЛЕЙ}

\section{С.М. Андреев, В.А. Жилин, А.С. Топчий}

Представлена методика применения библиотек компьютерного зрения для построения картографических моделей. Раскрыты особенности работы с типами данных на языке Pуthon, а также построена классификация библиотек языка Pуthоп в виде структурной схемы. Разработанная методика также предлагается в виде структурной схемы для лучшей её визуализации и упрощения понимания взаимодействия основных этапов работы при построении картографических моделей.

Ключевые слова: картография, типы и форматы данных, компьютерное зрение, программный ГІС-пакет.

\section{METHOD OF APPLICATION OF LIBRARIES OF COMPUTER VISION FOR CONSTRUCTION OF CARTOGRAPHIC MODELS}

\section{S.M. Andreev, V.A. Zhilin, A.S. Topchy}

The technique of application of libraries of computer sight for construction of cartographic models is presented. Features of working with data types in Python are disclosed, and a classification of Python libraries in the form of a structural scheme is constructed. The developed methodology is also proposed in the form of a structural scheme for better visualization and simplification of the understanding of the interaction of the main stages of work in the construction of cartographic models.

Keywords: cartography, types and formats of data, computer vision, software GIS package. 